\title{
Effect of trisodium citrate concentration on the particle growth of ZnS nanoparticles
}

\author{
Abdul Kareem Thottoli and Anu Kaliani Achuthan Unni
}

\begin{abstract}
ZnS nanoparticles were prepared by simple wet chemical precipitation method to study the effect of sulfur and trisodium citrate concentration on the particle growth of ZnS nanoparticles. Particle sizes were seen varied with the concentration of the sulfur and trisodium citrate. Compressive strain was observed only for a particular concentration of sulfur, and that sample was chosen for trisodium citrate experiments. Interestingly, the compressive strain was seen varied with the concentration of trisodium citrate and seen maximum for $2 \mathrm{M}$ concentration of trisodium citrate. Further, interband transition was observed in the case of smaller crystallites prepared in the trisodium citrate. It is clearly observed from the FTIR analysis that the trisodium citrate acts as a stabilizer and capped the particles from further growth.
\end{abstract}

Keywords: ZnS nanoparticles; Wet chemical preparation; Crystallites

\section{Background}

It is a well-known fact that the semiconductor nanoparticles exhibit novel optical, electronic, and physical properties than their bulk counterparts. When the size of the nanoparticles becomes less or comparable to the Bohr diameter of the exciton [1], various size quantization effects such as widening of band gap and formation of discrete orbitals come into the picture as explained by the Heisenberg uncertainty principle. Among the semiconducting nanoparticles, $\mathrm{ZnS}$ is one of the most important materials in the electronic/optoelectronic industry with prominent applications [2] in flat-panel displays [3], white light LEDs [4], electroluminescence devices [5], sensors [6], lasers [7], infrared windows [8], ultraviolet (UV) lasers [9], antireflection coating on solar cells [10], solar cells [11], and for investigating cellular interactions [12], for both in vivo-in vitro imaging applications [13], and memristor applications [14]. Basically, $\mathrm{ZnS}$ has negative conductivity $[15,16]$ and has a small exciton Bohr radius of about $2.5 \mathrm{~nm}$ [17]. Particle size reduction has a tremendous effect on the properties of the $\mathrm{ZnS}$ such as blueshift in the optical absorption spectrum, increased luminescence, enhanced oscillator strength, nonlinear optical effects, geometrical structure, chemical bonds, ionization

\footnotetext{
* Correspondence: abdulkareem.t@gmail.com

PG \& Research Department of Physics, Kongunadu Arts and Science College, GN Mills PO, Coimbatore, Tamilnadu 641 029, India
}

potential, mechanical strength, melting point, etc. Furthermore, $\mathrm{ZnS}$ relates more popular $\mathrm{ZnO}$ in terms of atomic structure and chemical properties. Certain properties of $\mathrm{ZnS}$ are unique and advantageous compared to that of $\mathrm{ZnO}$. ZnS has a larger band gap than that of $\mathrm{ZnO}$ (approximately $3.4 \mathrm{eV}$ [17]), and therefore, it is more suitable for visible UV light-based devices such as sensors/photodetectors. However, nano-sized $\mathrm{ZnS}$ has not been investigated in much detail compared to $\mathrm{ZnO}$ nanomaterials.

This paper discusses the preparation of zinc sulfide nanocrystals by simple wet chemical precipitation method [18-21] and studies the effect of the concentration of sulfur and trisodium citrate on nanoparticle formation since trisodium citrate acts as surfactant and capping agent that can modify the surface of $\mathrm{ZnS}$ particles and prevents the growth of the particles.

\section{Results and discussion}

$\mathrm{ZnS}$ nanocrystalline powder synthesis by varying sulfur concentration

The prepared $\mathrm{ZnS}$ powder samples were analyzed by powder X-ray diffraction technique, scanning electron microscopy (SEM), energy dispersive X-ray (EDX), and UV-visible absorption spectrophotometer. The X-ray diffractogram of the prepared samples well correlates with the American Society for Testing and Materials

\section{空}


(ASTM) card no. 77-2100 of cubic structure, and the diffraction peaks from the planes (111), (220), and (311) were noted in the diffractograms shown in Figure 1. All of the X-ray diffractogram peaks and the peak broadening confirmed that the prepared sample contains pure cubic $\mathrm{ZnS}$ nanocrystallites. Their crystallite size and the strain were obtained from the
Williomson-Hall plot [22]. The crystallite size, strain, lattice parameters, and the volume of the crystals of each sample are shown in Table 1, and it is seen that the prepared $\mathrm{ZnS}$ powder consists of nanoparticles. Table 1 clearly shows the compressive strain for the samples $\mathrm{ZnS}_{0.1}$ and $\mathrm{ZnS}_{0.05}$, a property of nanoparticles.

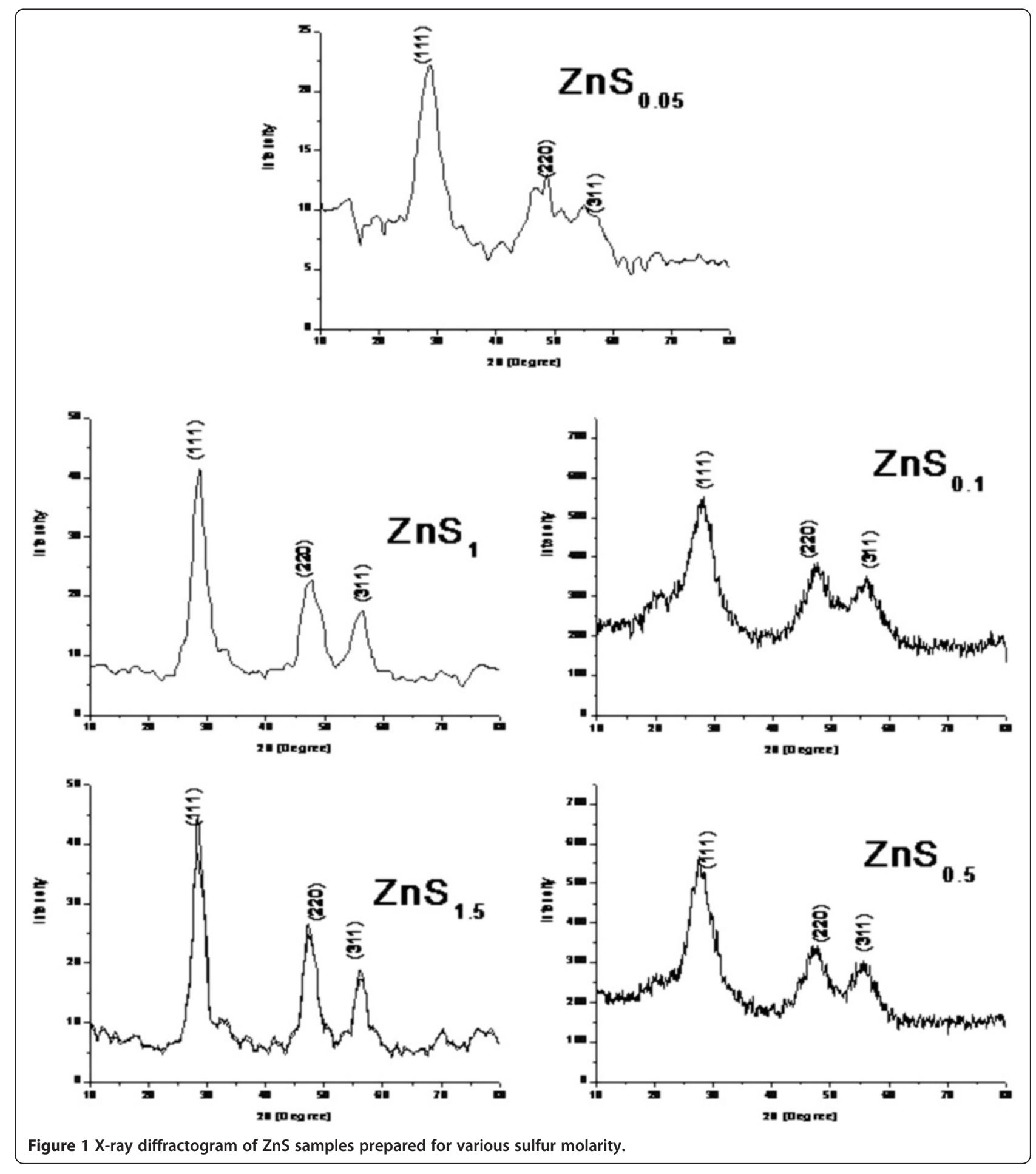


Table 1 Lattice parameters and volume of crystals

\begin{tabular}{|c|c|c|c|c|c|c|}
\hline \multirow[t]{2}{*}{ Samples } & \multicolumn{3}{|c|}{$\begin{array}{l}\text { Lattice parameters (ASTM values are } \\
\text { shown in bracket) ( } \AA \text { ) }\end{array}$} & \multirow[t]{2}{*}{$\begin{array}{l}\text { Average crystallite } \\
\text { size }(\mathrm{nm})\end{array}$} & \multirow[t]{2}{*}{$\begin{array}{l}\text { Average } \\
\text { strain }\end{array}$} & \multirow{2}{*}{$\begin{array}{l}\text { Volume }\left(10^{-28} \mathrm{~m}^{3} \text { ) }\right. \\
\text { (ASTM values are } \\
\text { shown in bracket) }\end{array}$} \\
\hline & $a$ & b & c & & & \\
\hline $\mathrm{ZnS}_{1.5}$ & $5.4159(5.4146)$ & - & - & 6.91 & 0.0279 & 1.5905 (1.5875) \\
\hline $\mathrm{ZnS}_{1}$ & $5.4106(5.4146)$ & - & - & 5.35 & 0.0441 & 1.5839 (1.5875) \\
\hline $\mathrm{ZnS}_{0.5}$ & $5.5138(5.4146)$ & - & - & 2.91 & 0.0265 & $1.6763(1.5875)$ \\
\hline $\mathrm{ZnS}_{0.1}$ & $5.4289(5.4146)$ & - & - & 2.43 & -0.0167 & $1.6001(1.5875)$ \\
\hline $\mathrm{ZnS}_{0.05}$ & $5.3949(5.4146)$ & - & - & 2.90 & -0.0351 & $1.5702(1.5875)$ \\
\hline
\end{tabular}
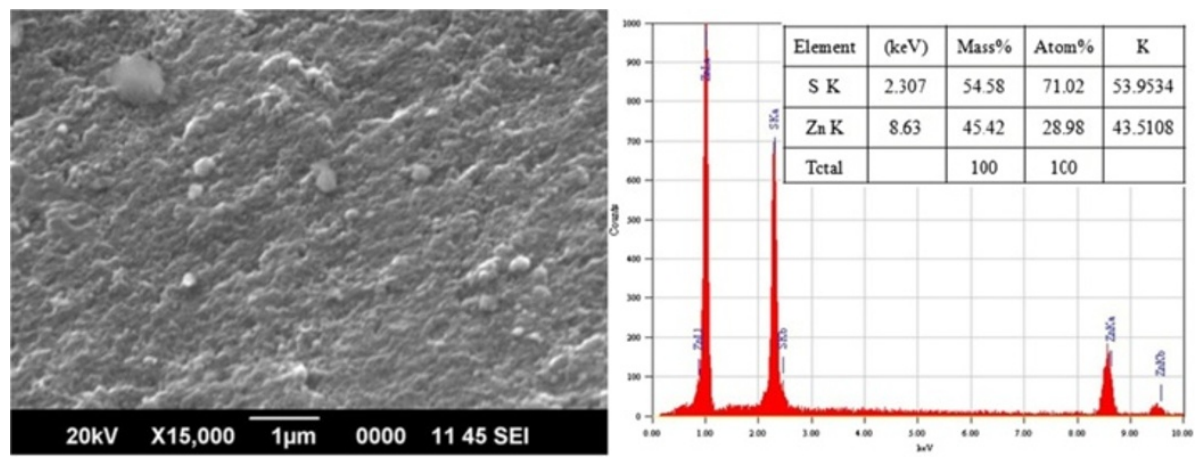

Figure $2 \mathrm{SEM}$ micrograph and EDX of $\mathrm{ZnS}$ prepared with $1 \mathrm{M} \mathrm{Na}_{2} \mathrm{~S}$ solution $\left(\mathrm{ZnS}_{1}\right)$.
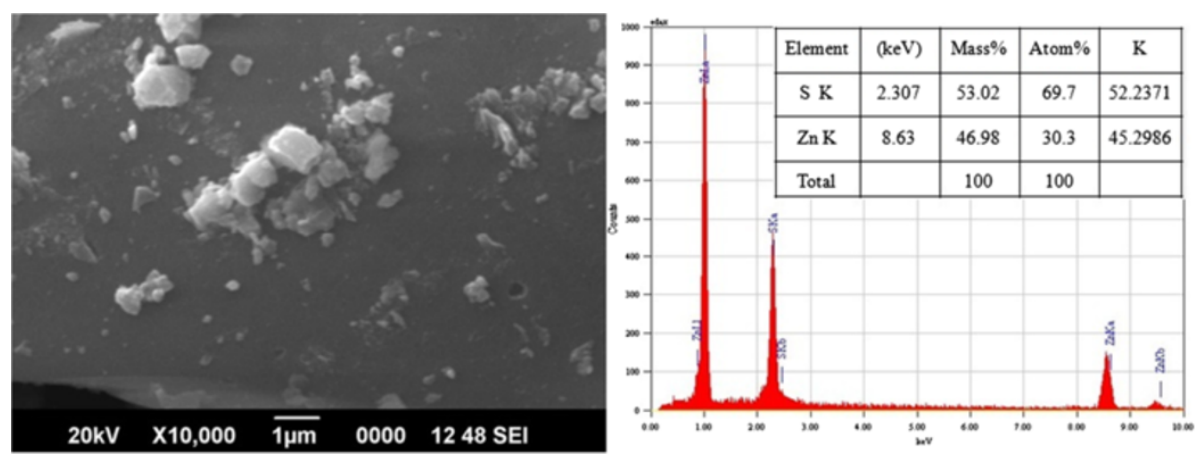

Figure $3 \mathrm{SEM}$ micrograph and EDX of $\mathrm{ZnS}$ prepared with $0.5 \mathrm{M} \mathrm{Na}_{2} \mathrm{~S}$ solution $\left(\mathrm{ZnS}_{0.5}\right)$.
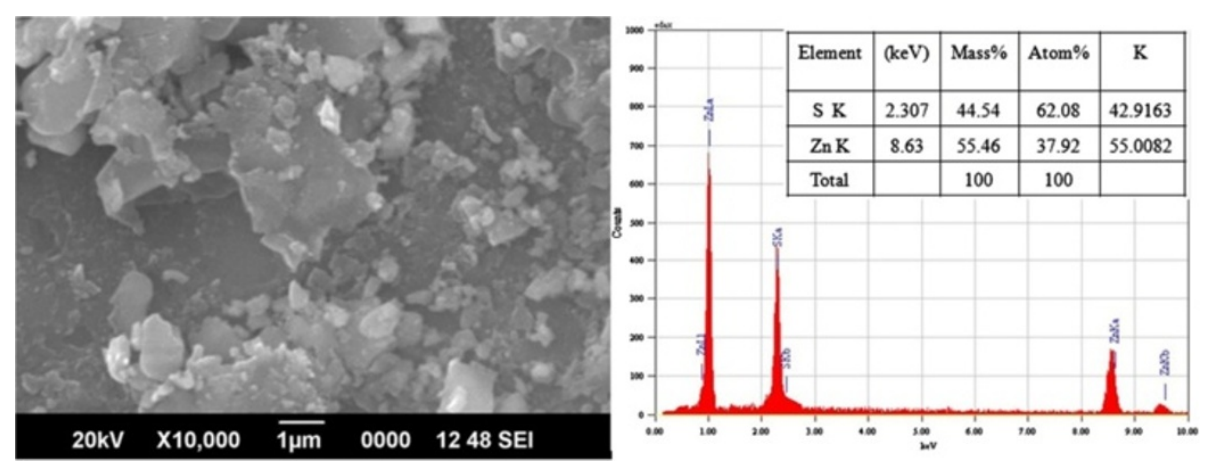

Figure 4 SEM micrograph and EDS of $\mathrm{ZnS}$ prepared with $0.1 \mathrm{M} \mathrm{Na}_{2} \mathrm{~S}$ solution $\left(\mathrm{ZnS}_{0.1}\right)$. 


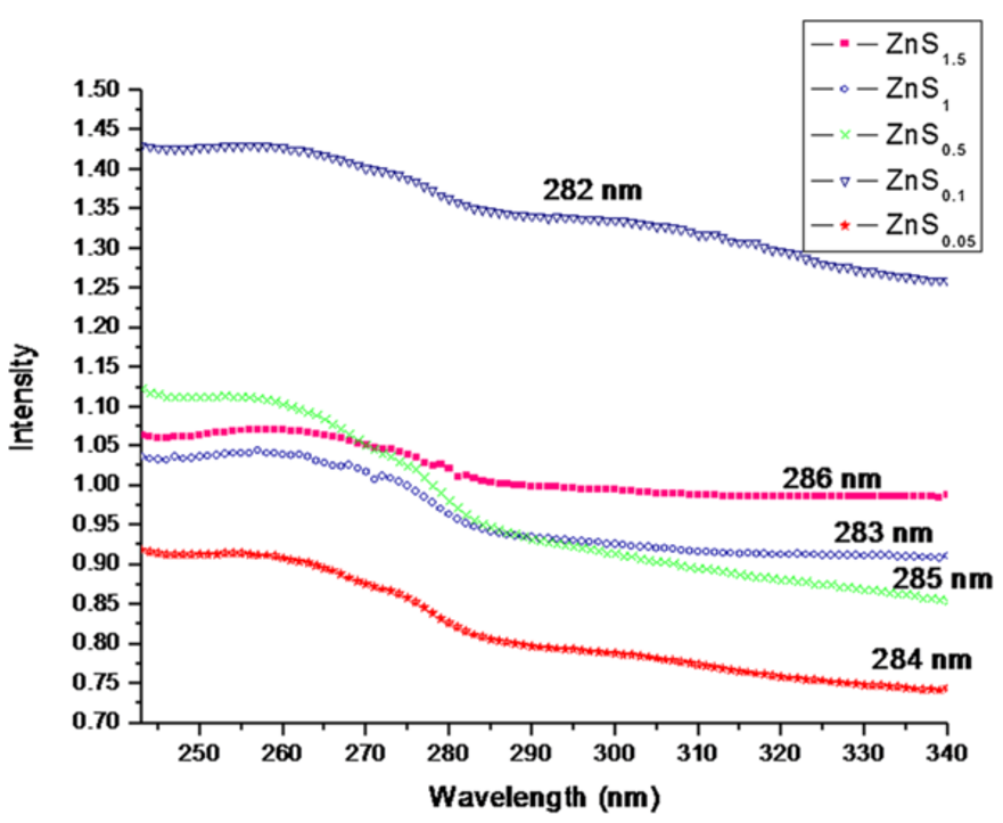

Figure 5 Absorption spectrograph of $\mathrm{ZnS}$ prepared in various concentrations of $\mathrm{Na}_{2} \mathrm{~S}$ solution.

EDX analysis of smaller crystallite samples were performed to find their elemental composition, and the results are shown in Figures 2, 3, and 4, where the elemental data are shown in the inset tables of Figures 2, 3, and 4. These data confirm that the prepared powder consist of only $\mathrm{ZnS}$ compound as seen from the X-ray diffractograms of those samples (Figure 1).

To obtain the visual image of the nanoparticles, these nanocrystalline powder samples were analyzed by SEM, and the micrographs are shown in Figures 2, 3 , and 4. All of the SEM micrographs reveal that the nanograins are agglomerated due to the drying process, and the sizes of the particles are much larger than the values found from the XRD data. The discrepancy associated with the size of $\mathrm{ZnS}$ nanoparticles found from XRD and SEM may be because of the fact that SEM shows the lateral dimension of the particles whereas XRD gives the regularity in the atomic arrangement. Perhaps the lateral dimension is of the order of a few tens of nanometers, but the individual nanoparticle with regular atomic lattice extends only up to a few nanometers.

The study of optical absorption is important to understand the behavior of semiconductor nanocrystals since the fundamental property of semiconductors is the band gap that is the energy separation between the filled valence band and the empty conduction band. The optical excitation of electrons across the band gap is strongly allowed that produces an abrupt increase in absorption at the wavelength corresponding to the band gap energy. This feature of the optical spectrum is known as the optical absorption edge. High-quality $\mathrm{ZnS}$ structures have good ultraviolet optical properties at room temperature, and Figure 5 shows the optical absorption spectra of the prepared $\mathrm{ZnS}$ nanoparticles which is in the range of 800 to $200 \mathrm{~nm}$. The absorption edge was obtained at shorter wavelengths compared to the absorption edge of the bulk materials due to the increase in band gap as a result of the quantum confinement effect as well as the discrete energy bands. Strong confinement is observed when the crystallite or particle size is smaller than the Bohr exciton radius of $\mathrm{ZnS}$ (approximately $2.5 \mathrm{~nm}$ [23]) as a result of this strong confinement absorption peaks which appear in the absorption spectra due to subband transitions, so that in this case, band gap can be found from the maximum of this absorption peak. However, when the crystallite size increases above the Bohr radius, the peak structure disappears and attains the normal interband transition spectrum [24] having an absorption edge at a lower wavelength than the bulk

Table 2 Crystallite size and band gap

\begin{tabular}{lllll}
\hline Samples & $\begin{array}{l}\text { Crystallite } \\
\text { size }(\mathbf{n m})\end{array}$ & $\begin{array}{l}\text { Band gap from } \\
\text { Brus equation } \\
\text { (1) (eV) }\end{array}$ & $\begin{array}{l}\text { Band gap from } \\
\text { absorption } \\
\text { spectra (eV) }\end{array}$ & $\begin{array}{l}\text { Absorption } \\
\text { edge (nm) }\end{array}$ \\
\hline $\mathrm{ZnS}_{1.5}$ & 6.91 & 3.75 & 4.33 & 286 \\
\hline $\mathrm{ZnS}_{1}$ & 5.35 & 3.83 & 4.38 & 283 \\
\hline $\mathrm{ZnS}_{0.5}$ & 2.91 & 4.37 & 4.35 & 285 \\
\hline $\mathrm{ZnS}_{0.1}$ & 2.43 & 4.71 & 4.40 & 282 \\
\hline $\mathrm{ZnS}_{0.05}$ & 2.90 & 4.37 & 4.37 & 284 \\
\hline
\end{tabular}




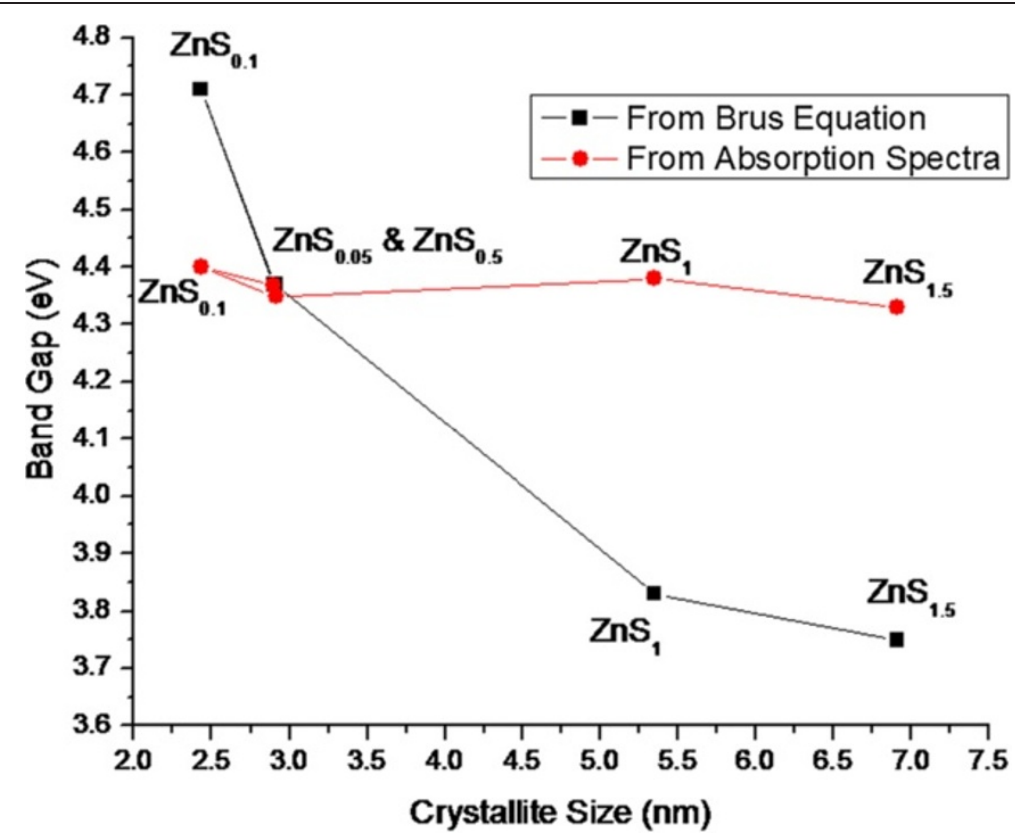

Figure 6 Crystallite size vs band gap.
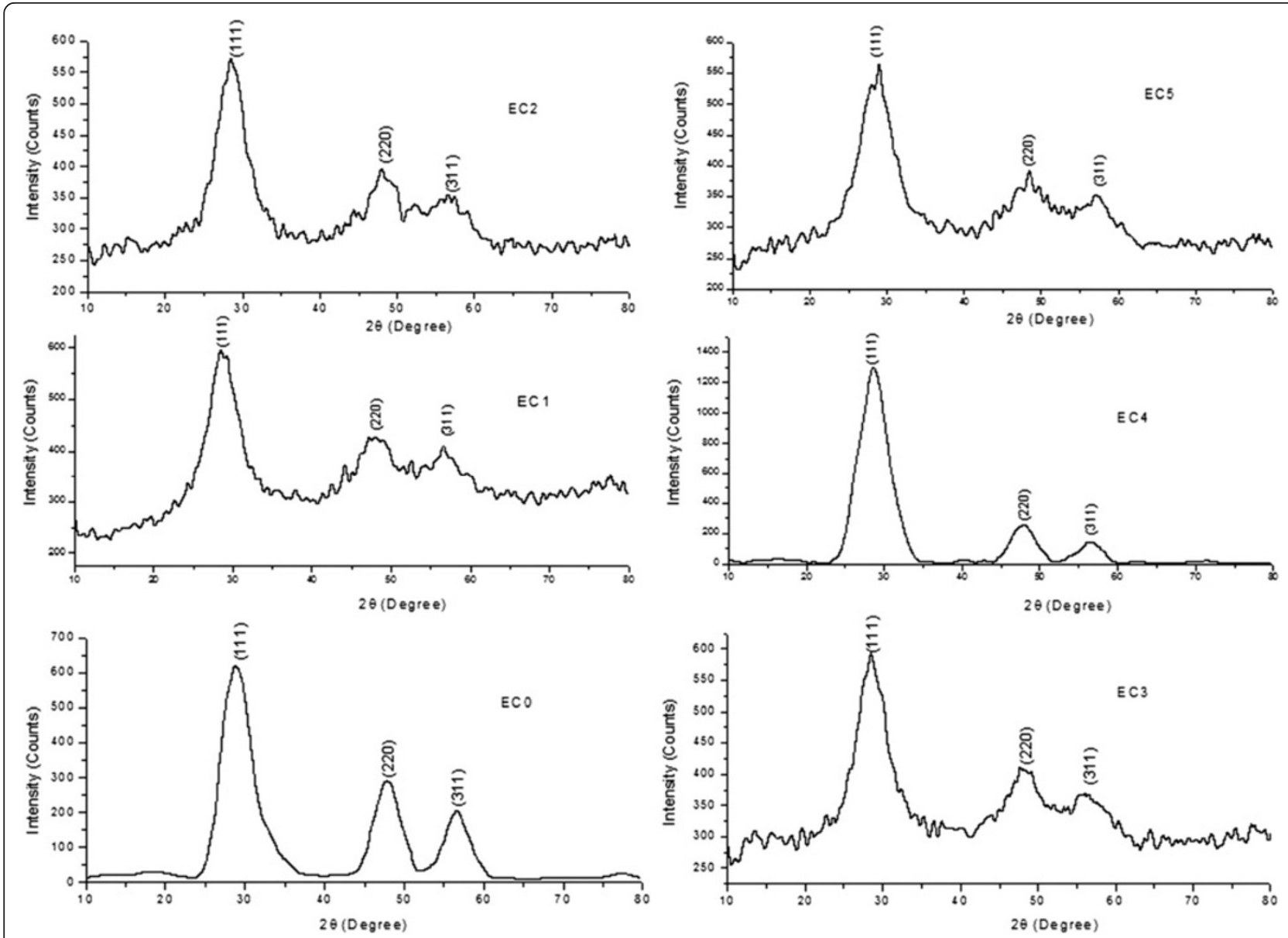

Figure 7 X-ray diffractogram of the samples of various citrate concentrations. 


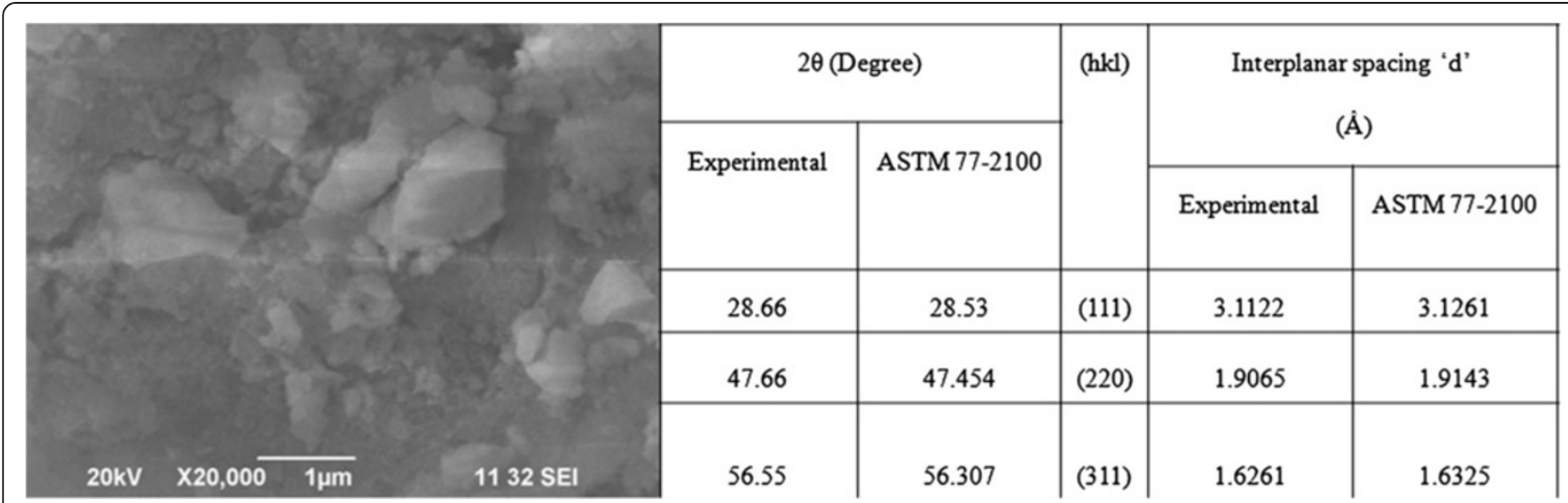

Figure 8 SEM image and XRD information of ZnS prepared without any surfactant (C0).

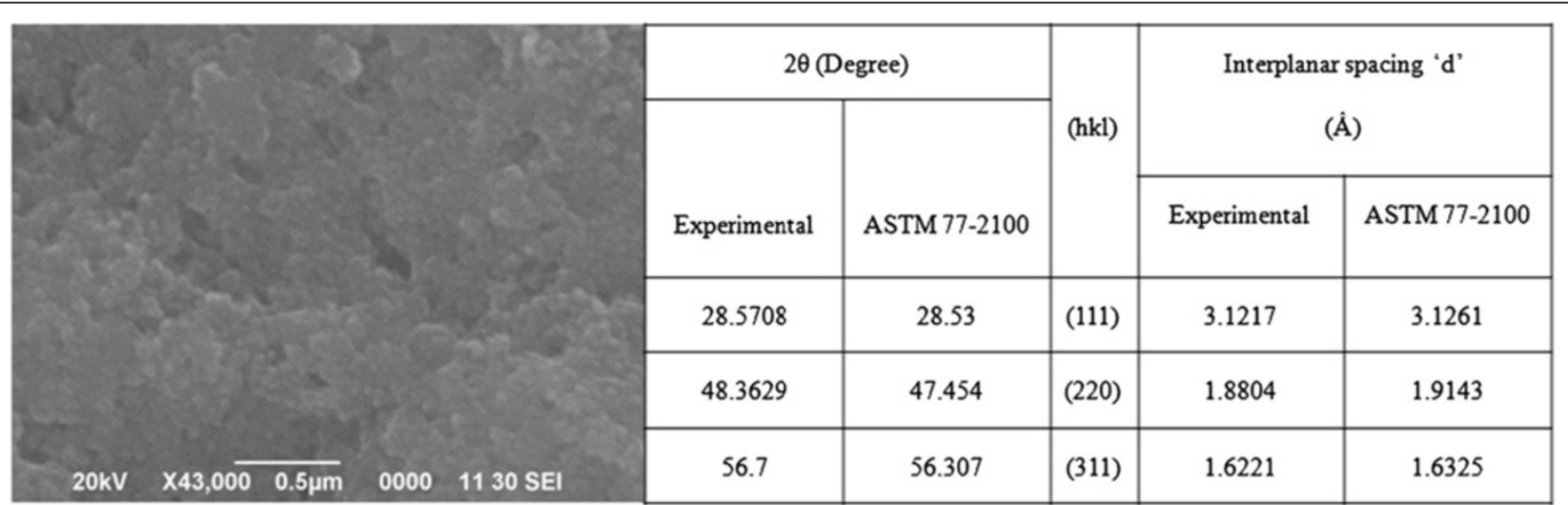

Figure 9 SEM image and XRD information of ZnS prepared in $0.5 \mathrm{M}$ concentration of trisodium citrate (C1).

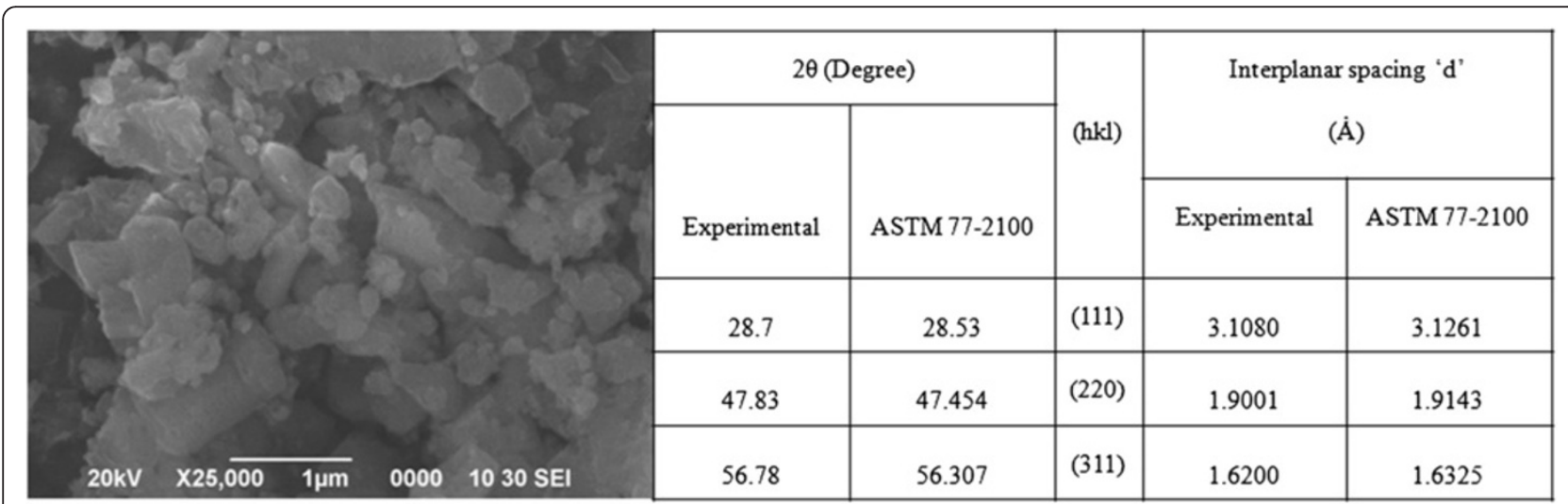

Figure 10 SEM image and XRD information of ZnS prepared in $1 \mathrm{M}$ concentration of trisodium citrate (C2). 


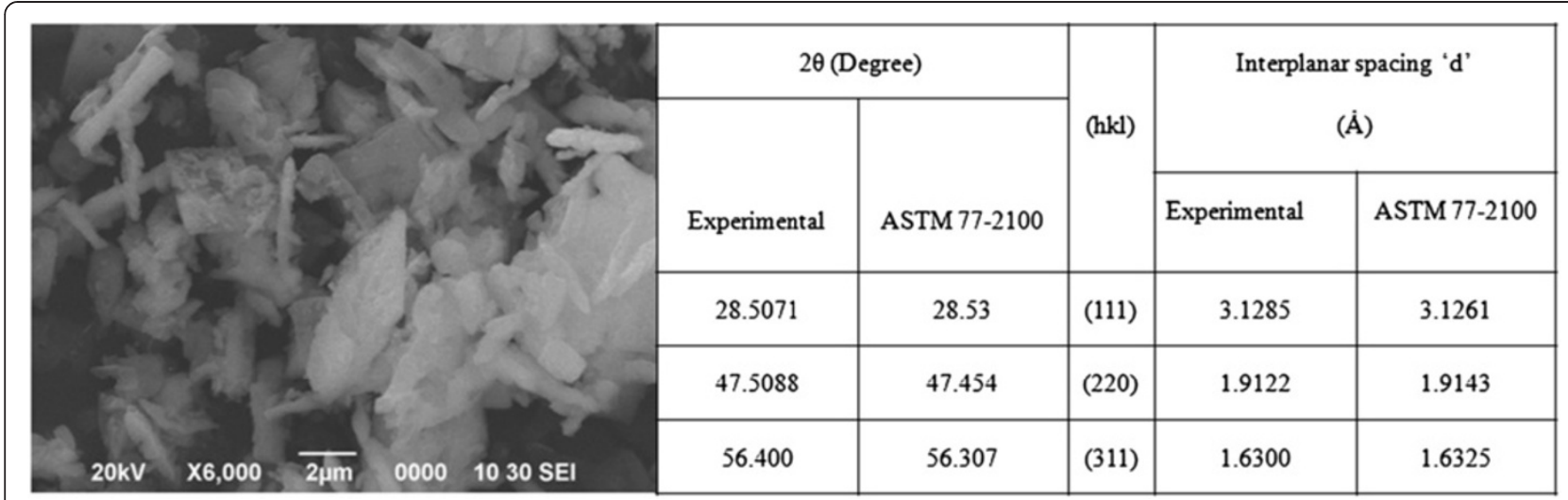

Figure $11 \mathrm{SEM}$ image and XRD information of ZnS prepared in $1.5 \mathrm{M}$ concentration of trisodium citrate (C3).

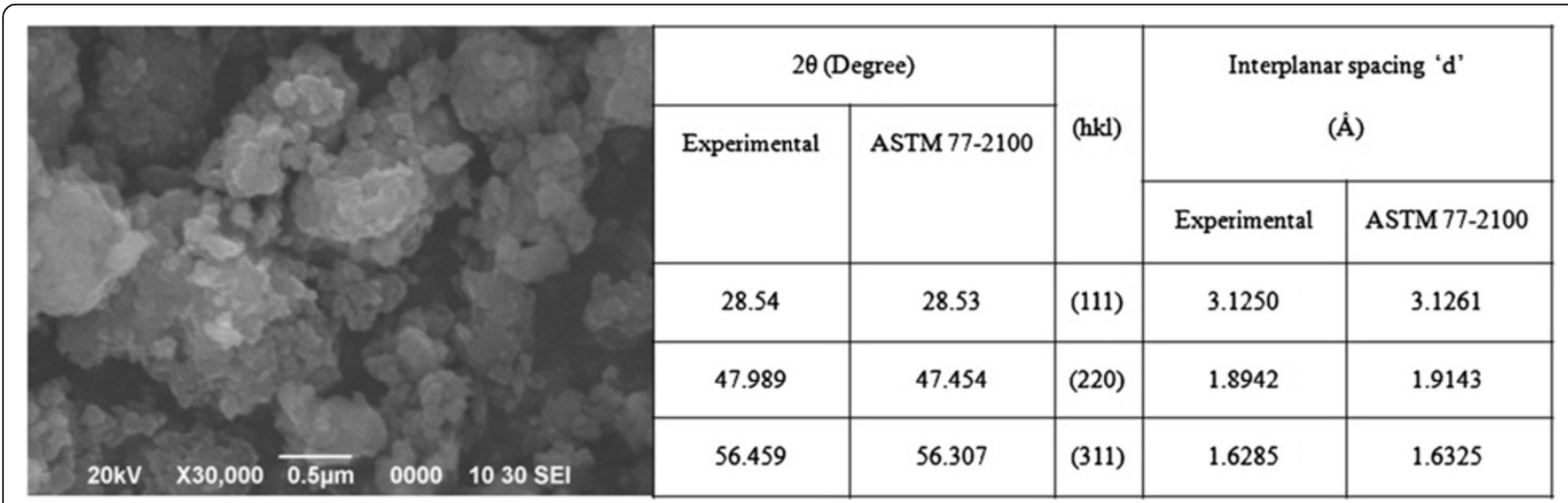

Figure 12 SEM image and XRD information of ZnS prepared in $2 \mathrm{M}$ concentration of trisodium citrate (C4).

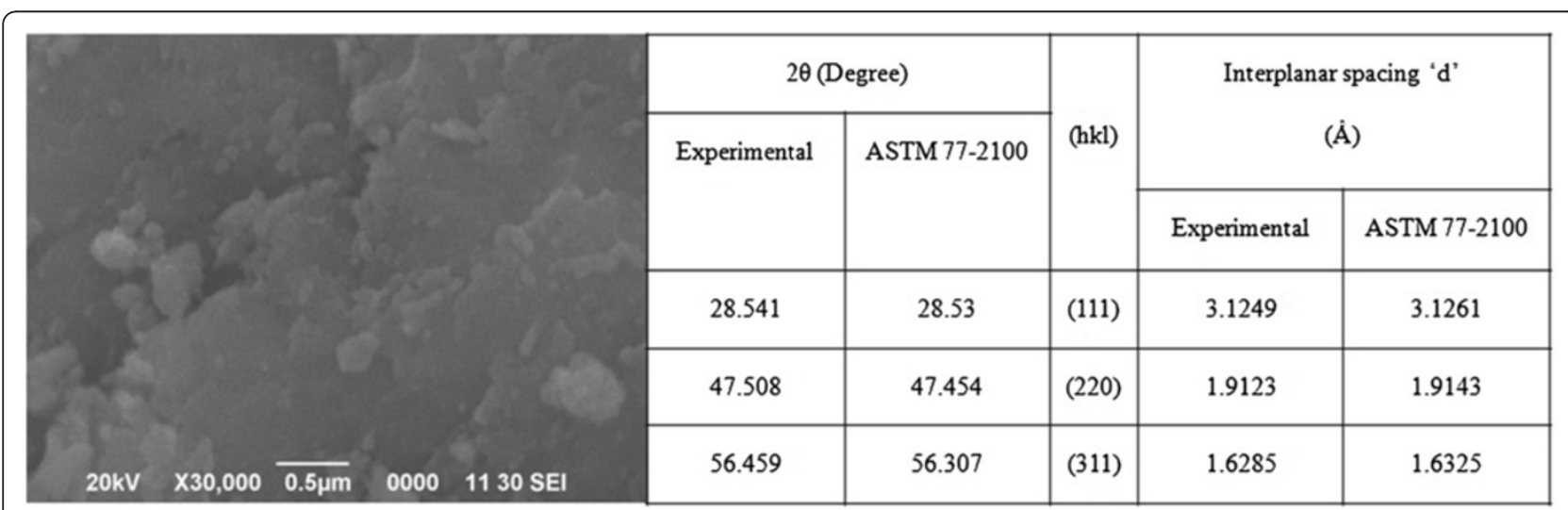

Figure 13 SEM image and XRD information of ZnS prepared in $3 \mathrm{M}$ concentration of trisodium citrate (C5). 
Table 3 Lattice parameters, crystallite size, strain, and volume of crystals

\begin{tabular}{|c|c|c|c|c|c|c|}
\hline \multirow[t]{2}{*}{ Samples } & \multicolumn{3}{|c|}{$\begin{array}{l}\text { Lattice parameters } \\
\text { (ASTM value in } \\
\text { brackets) (̊̊) }\end{array}$} & \multirow[t]{2}{*}{$\begin{array}{l}\text { Average } \\
\text { crystallite } \\
\text { size }(\mathrm{nm})\end{array}$} & \multirow[t]{2}{*}{$\begin{array}{l}\text { Average } \\
\text { strain }\end{array}$} & \multirow{2}{*}{$\begin{array}{l}\text { Volume } \\
\left(10^{-28} \mathrm{~m}^{3}\right) \\
\text { (ASTM value } \\
\text { in brackets) }\end{array}$} \\
\hline & $\mathrm{a}$ & b & $\bar{c}$ & & & \\
\hline $\mathrm{CO}$ & $5.3921(5.4146)$ & - & - & 2.94 & -0.0136 & $1.5677(1.5874)$ \\
\hline $\mathrm{C1}$ & $5.3686(5.4146)$ & - & - & 1.74 & -0.0 & $1.5474(1.5874)$ \\
\hline 2 & $5.3769(5.4146)$ & - & 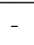 & 1.73 & -0.0872 & $1.5545(1.5874)$ \\
\hline $\mathrm{C} 3$ & $5.4113(5.4146)$ & - & - & 2.25 & -0.0341 & $1.5846(1.5874)$ \\
\hline $\mathrm{C4}$ & $5.3906(5.4146)$ & - & - & 1.46 & -0.0119 & $1.5664(1.5874)$ \\
\hline 5 & $5.4075(5.4146)$ & - & - & 1.95 & -0.0531 & $1.5812(1.5874)$ \\
\hline
\end{tabular}

materials. In the bulk material or in thin films, the band gap can be found from the plot between $(\alpha h v)^{2}$ vs $h v$, whereas in the nanomaterials of sizes above Bohr radius, the band gap is obtained from the absorption edge, but when the nanomaterial size is less than Bohr exciton radius of the materials, it is obtained from the absorption peak.

When comparing the absorption spectrogram of each of the samples, it is well clear that the $\mathrm{ZnS}$ nanocrystalline powder prepared with $0.1 \mathrm{M}$ of $\mathrm{Na}_{2} \mathrm{~S}$ has the highest absorption intensity. Highest intensity of absorption means that there is a higher number of particles to absorb as well as this sample has the highest capacity to absorb the incident light. Each of the samples has the absorption around $280 \mathrm{~nm}(4.4 \mathrm{eV})$ which was blueshifted from 336 $\mathrm{nm}(3.7 \mathrm{eV})$ of the bulk $\mathrm{ZnS}$ [25]. The blueshifted absorption also confirms that the results obtained from the X-ray diffractograms and the SEM micrographs, that the powder samples are made up of nanocrystals, since the reduction in the size of particles leads to widening of the band gap and this widening is observable in the optical absorption spectra, where a blueshift is observed with the reduction in particle size. Brus [26] has proposed a theoretical model relating the effective band gap of a material with the particle size. The simple model predicting the variation of exciton energy with particle size is based on the effective mass approximation. The lowest excited state of the crystallite is assumed to be the ground state of an electron hole pair. The ground state energy of an exciton or the increase in effective band gap as a function of crystalline size is estimated as

$$
E_{\mathrm{g}}(r)=E_{\mathrm{g}, \text { bulk }}+\frac{h^{2}}{8 r^{2}}\left(\frac{1}{m_{e}}+\frac{1}{m_{h}}\right)-1.8 \frac{e^{2}}{4 \pi \varepsilon_{r} \varepsilon_{0} r}
$$

where $E_{g}(r)$ is the band gap of the nanoparticle, $E_{g, b u l k}$ is the bulk semiconductor band gap (approximately $3.68 \mathrm{eV}$ for Cubic ZnS [25], approximately $3.9 \mathrm{eV}$ for Wurtzite $\mathrm{ZnS}$ [25]), $h$ is Planck's constant $\left(6.6260 \times 10^{-34} \mathrm{~m}^{2} \mathrm{~kg} / \mathrm{s}\right.$ or $\left.4.1356 \times 10^{-15} \mathrm{eV} \cdot \mathrm{s}\right), \varepsilon_{r}$ is the relative dielectric constant of the material (8.6 [25]), $\varepsilon_{\mathrm{o}}$ is the permittivity of free space, $r$ is the radius of the particle, and $m_{e}$ and $m_{h}$ are the effective masses of the electron (approximately $0.3 m_{e}$ for $\mathrm{ZnS}$ [27]) and hole (approximately $0.6 m_{e}$ for $\mathrm{ZnS}$ [27]), respectively. Using the average crystallite size obtained from X-ray diffractograms, the band gap for each sample is calculated in Table 2. It is clear from Table 2 and Figure 6 that the band gap increases as the crystallite size decreases, and it is found that the sample $\mathrm{ZnS}_{0.1}$ possesses the smallest crystallites and has high absorption as well as higher band gap when compared with other samples, so that the stoichiometry of the $\mathrm{ZnS}_{0.1}$ was selected for further experiments.

\section{Effect of trisodium citrate concentration}

Here, trisodium citrate acts as a surfactant, and it allows easy spreading and lowering the surface tension of the solvent. Further, it acts as a microreactor for hosting the reaction and a steric stabilizer to inhibit the aggregation. $\mathrm{X}$-ray diffractogram of the samples was compared with the standard ASTM cards of $\mathrm{ZnS}$ and $\mathrm{ZnO}$, and it is found

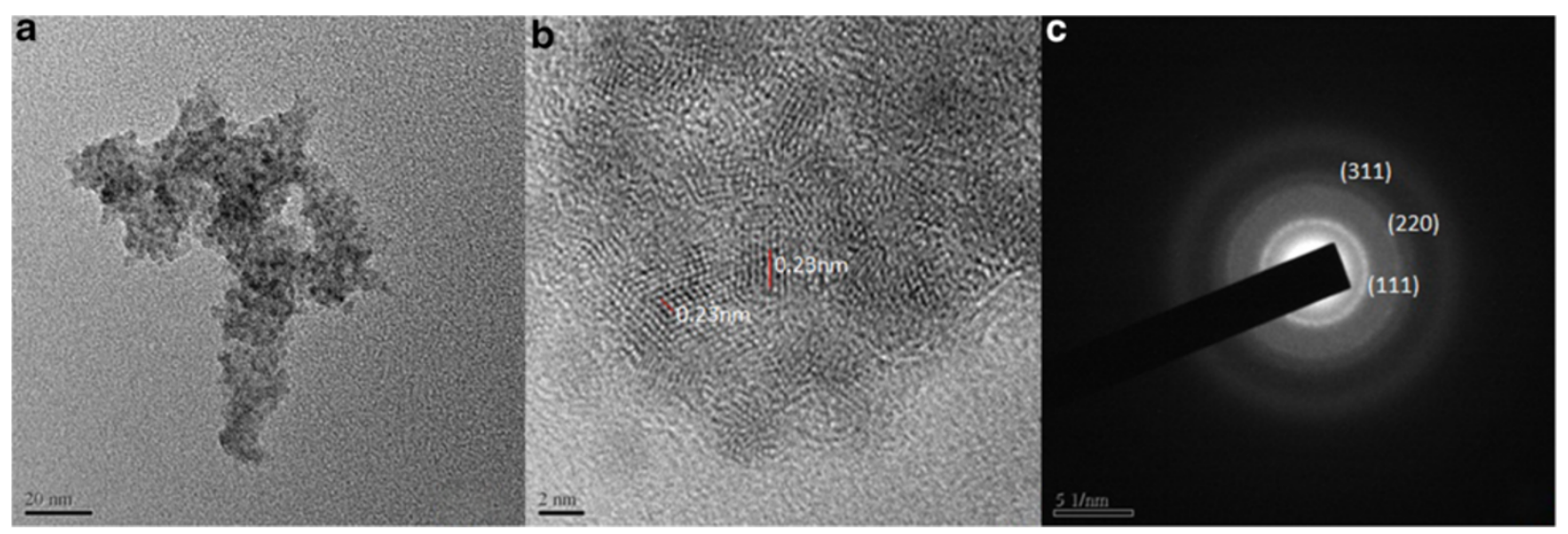

Figure 14 (a) TEM, (b) HRTEM, and (c) SAED images of ZnS prepared in $2 \mathrm{M}$ concentration of citrate (C4). 
Table 4 Comparison of interplanar spacing of sample C4 from different analyses

\begin{tabular}{llllll}
\hline Sample & $\begin{array}{l}\text { ASTM 77-2100 } \\
(\mathbf{n m})\end{array}$ & $\begin{array}{l}\text { XRD } \\
(\mathbf{n m})\end{array}$ & $\begin{array}{l}\text { SAED } \\
(\mathbf{n m})\end{array}$ & $\begin{array}{l}\text { HRTEM } \\
\mathbf{( n m )}\end{array}$ & Planes \\
\hline C4 & 0.3126 & 0.3125 & 0.30 & 0.23 & $(111)$ \\
\cline { 2 - 6 } & 0.1914 & 0.1894 & 0.18 & - & $(220)$ \\
\cline { 2 - 6 } & 0.1632 & 0.1628 & 0.15 & - & $(311)$ \\
\hline
\end{tabular}

that all the diffractograms correlate with the ASTM card of ZnS 77-2100 (cubic). Their X-ray diffractograms are shown in Figure 7, and their broadened peaks reveal that the sample consisted of nano-sized crystallites. Interplanar spacing of the crystals was calculated and compared with ASTM data in the table given with Figures 8, 9, 10, 11, 12, and 13. Average crystallite sizes and strain were obtained from Williamson-Hall plot [22], and other crystal information is given in Table 3 . It is seen from Table 3 that the $\mathrm{ZnS}$ crystals prepared in trisodium citrate have smaller crystal size when compared to the sample without this surfactant and formed various sizes of crystallites depending on the concentrations of the surfactants. Further, all of the samples show compressive strain, a property of nanomaterials. From all these experiments, $\mathrm{ZnS}$ prepared in $2 \mathrm{M}$ of citrate has the lowest size of crystallites which is evident from Table 3 . SEM micrographs of the samples shown in Figures 8, $9,10,11,12$, and 13 and the images reveal that welldispersed particles of nanocrystallites have been formed as observed from the X-ray diffractogram. From this analysis, it is obvious that the $\mathrm{ZnS}$ particle growth can be controlled by the concentration of the surfactant sodium citrate.

Reported works of John et al. [28] and Yuan-yuan [20] on $\mathrm{ZnS}$ nanostructures without any surfactants show larger particles (12 and $35 \mathrm{~nm}$, respectively) when compared to

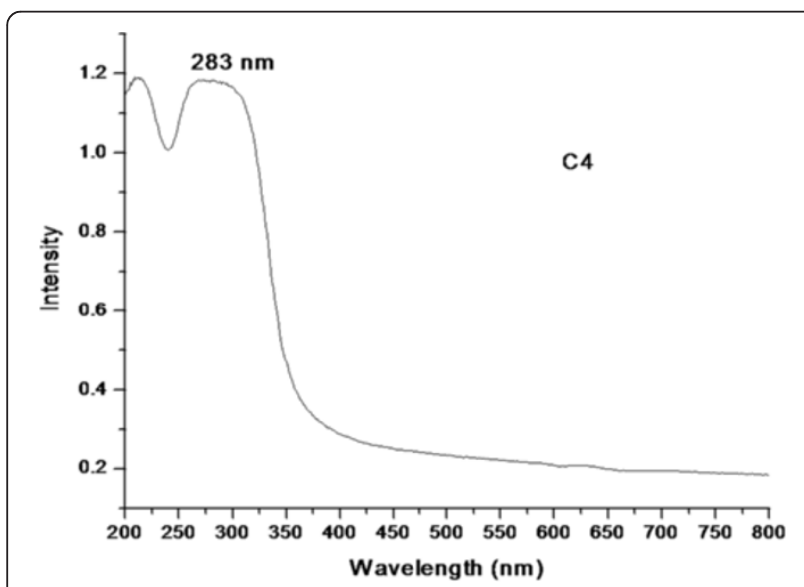

Figure 15 Absorption spectra of the $\mathrm{ZnS}$ prepared in $2 \mathrm{M}$ trisodium citrate.
Table 5 Crystallite size and band gap of the ZnS prepared in $\mathbf{2} \mathrm{M}$ trisodium citrate

\begin{tabular}{lll}
\hline Crystallite size (nm) & $\begin{array}{l}\text { Band gap from Brus } \\
\text { equation (1) }(\mathrm{eV})\end{array}$ & $\begin{array}{l}\text { Band gap from } \\
\text { absorption spectra }(\mathrm{eV})\end{array}$ \\
\hline 1.46 & 6.82 & 4.38
\end{tabular}

the work explained in this paper (1.46 to $2.25 \mathrm{~nm}$ ). This comparison on particle size with the previous works $[20,28]$ also showed that surfactant sodium citrate has influence on the crystallization of $\mathrm{ZnS}$ nanocrystals.

Further, the sample prepared in $2 \mathrm{M}$ of trisodium citrate was analyzed by transmission electron microscopy (TEM) by dispersing the powder in ethanol. Figure 14 shows the TEM, high-resolution transmission electron microscopy (HRTEM), and selected area electron diffraction (SAED) images of this sample, and it is explicitly shown that the particles are well below $10 \mathrm{~nm}$. The polycrystalline diffraction rings of the SAED images are labeled to the corresponding planes according to the ASTM card of ZnS 772100 (cubic). The interplanar spacing of $0.23 \mathrm{~nm}$ found from HRTEM matches with the (111) planes which is smaller than the XRD data since the powder was dispersed in ethanol for TEM analysis that disintegrate the agglomerated particles and that further compresses the crystallites. The interplanar spacing (d) obtained from different analysis are compared in Table 4.

Optical absorption spectrum of the $\mathrm{ZnS}$ prepared in 2 $\mathrm{M}$ citrate is shown in Figure 15, and the appearance of the peak shows interband transitions due to the strong quantum confinement effect. The band gap of the sample is calculated and shown in Table 5 with the crystallite size. It is seen that the band gap calculated from the Brus equation is larger than the band gap obtained from the absorption spectra, which shows that the Brus equation cannot be expected to be quantitatively correct for very small particles [29], since the absorption in the case of small particles having size smaller than their exciton Bohr radius is due to the interband transition. Further, the agglomeration of the nanoparticles also has an effect in their absorption spectra.

Fourier transform infrared spectroscopy (FTIR) analysis was performed after dispersing the powder in ethanol to find the presence of trisodium citrate in the final product that helps to differentiate the properties of the pure $\mathrm{ZnS}$ nanocrystals with the $\mathrm{ZnS}$ nanocrystals with trisodium citrate. The FTIR spectra of the trisodium citrate, $\mathrm{ZnS}$ prepared without trisodium citrate, and $\mathrm{ZnS}$ prepared with citrate (sample C4) are shown in Figure 16, and the absorption bands are assigned to the respective vibrations as shown in Table 6. The FTIR spectra show that $\mathrm{ZnS}$ is covered with the surfactant trisodium citrate. 


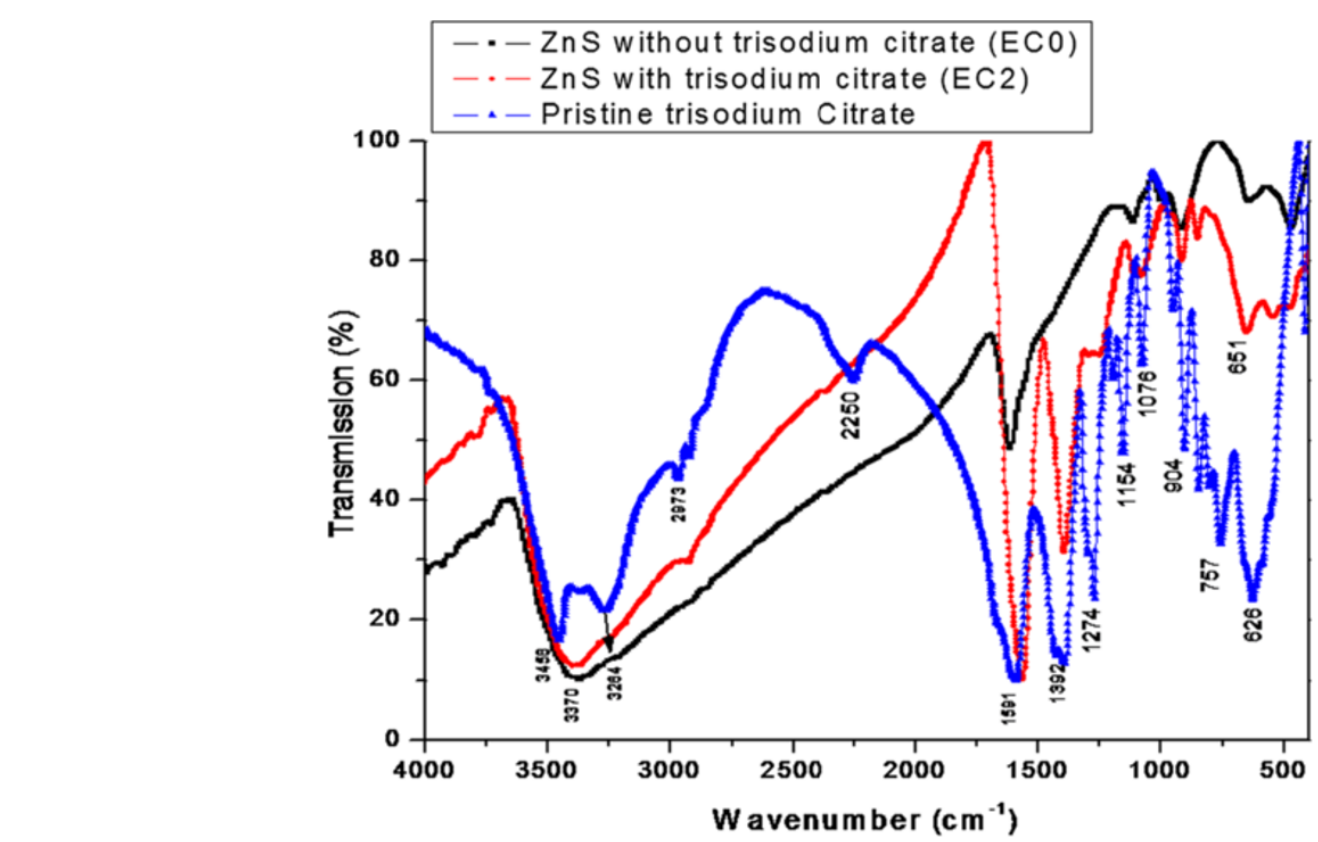

Figure 16 FTIR spectra of Trisodium citrate and ZnS with and without trisodium citrate.

\section{Conclusions}

The preparation of zinc sulfide nanocrystals by simple wet chemical precipitation method is discussed here. It is found that the concentration of sulfur and trisodium citrate has tremendous effect on $\mathrm{ZnS}$ nanoparticle formation. The particle size was seen to depend on the concentration of trisodium citrate, and the dependence of the optical behavior on Bohr exciton radius of the ZnS nanoparticles was observed.

\section{Methods}

ZnS nanocrystalline powder synthesis by varying sulfur concentration

It is essential to find a suitable reagent concentration and stoichiometry for $\mathrm{ZnS}$ nanoparticles preparation, and therefore, it was decided to fix the concentration of $\mathrm{Zn}$ precursor $\left(\mathrm{ZnCl}_{2}\right)$ and the surfactant trisodium citrate and to vary the concentration of the sulfur precursor $\left(\mathrm{Na}_{2} \mathrm{~S}\right)$. These studies revealed the suitable $\mathrm{Zn}$ precursor and sulfur precursor concentrations for processing $\mathrm{ZnS}$ nanocrystallites.

$\mathrm{ZnS}$ samples were prepared by varying the sulfur concentration from 0.05 to $1.5 \mathrm{M}$, and the samples were named as $\mathrm{ZnS}_{0.05}, \mathrm{ZnS}_{0.1}, \mathrm{ZnS}_{0.5}, \mathrm{ZnS}_{1}$, and $\mathrm{ZnS}_{1.5}$. For this experiment, $50-\mathrm{ml}$ stock solution of $1 \mathrm{M} \mathrm{ZnCl}_{2}$ and $0.5 \mathrm{M}$ trisodium citrate was prepared in deionized (DI) water and concentration of $\mathrm{Na}_{2} \mathrm{~S}$ was varied as shown in Table 7 . Trisodium citrate solution $(0.5 \mathrm{M})$ was added to each of the $\mathrm{Na}_{2} \mathrm{~S}$ solution and stirred well for $1 \mathrm{hr}$ at room temperature. Then, each of the 10.5- $\mathrm{ml} \mathrm{Na}_{2} \mathrm{~S}$ trisodium citrate solution was added dropwise using a burette to the $10-\mathrm{ml} \mathrm{ZnCl}_{2}$ solution while continuing the stirring $(200 \mathrm{rpm})$ at room temperature. It was found that the color of the solution changed from a transparent

Table 6 FTIR peak assignments of trisodium citrate and ZnS with and without trisodium citrate

\begin{tabular}{|c|c|c|c|c|c|c|c|}
\hline \multicolumn{4}{|c|}{ Citrate } & \multirow{2}{*}{$\begin{array}{l}\text { ZnS without } \\
\text { citrate (CO) }\end{array}$} & \multirow{2}{*}{$\begin{array}{l}\text { Peak } \\
\text { assignment }\end{array}$} & \multirow{2}{*}{$\begin{array}{l}\text { ZnS with } \\
\text { citrate (C4) }\end{array}$} & \multirow[t]{2}{*}{ Peak assignments } \\
\hline Peaks & Peak assignment & Peaks & Peak assignment & & & & \\
\hline 3458 & $\mathrm{O}-\mathrm{H}$ stretching & 1193 & C-O stretching & 3370 & $\mathrm{O}-\mathrm{H}$ stretching & 3399 & $\mathrm{O}-\mathrm{H}$ stretching \\
\hline 3264 & $\mathrm{O}-\mathrm{H}$ stretching & 1154 & C-O stretching & 1615 & $C-C$ & 1563 & $\mathrm{C}=\mathrm{O}$ stretching \\
\hline 2973 & $\mathrm{C}-\mathrm{H}$ bending & 1076 & C-O stretching & 1115 & C-O stretching & 1394 & $\mathrm{C}-\mathrm{H}$ bending \\
\hline 2921 & $\mathrm{C}-\mathrm{H}$ bending & 949 & C-O stretching & 1002 & C-O stretching & 1293 & C-O asymmetrical stretching \\
\hline 2250 & $\mathrm{C}=\mathrm{O}$ stretching & 904 & $\mathrm{C}-\mathrm{H}$ bending & 920 & $\mathrm{C}-\mathrm{H}$ bending & 1077 & C-O asymmetrical stretching \\
\hline 1591 & $\mathrm{C}=\mathrm{O}$ stretching & 845 & $\mathrm{C}-\mathrm{H}$ bending & 642 & $\mathrm{O}-\mathrm{H}$ bending & 913 & $\mathrm{C}-\mathrm{H}$ bending \\
\hline 1392 & $\mathrm{C}-\mathrm{H}$ bending & 757 & $\mathrm{C}-\mathrm{H}$ bending & - & - & 849 & $\mathrm{C}-\mathrm{H}$ bending \\
\hline 1274 & C-O stretching & 626 & $\mathrm{C}-\mathrm{H}$ deformation & - & - & 651 & $\mathrm{C}-\mathrm{H}$ bending \\
\hline
\end{tabular}


Table 7 Concentration of $\mathrm{Na}_{2} \mathrm{~S}$ for finding suitable stochiometry

\begin{tabular}{llll}
\hline Samples & Number of moles & Molarity (M) & Color of the product \\
\hline $\mathrm{ZnS}_{1.5}$ & 0.015 & 1.5 & light yellow \\
\hline $\mathrm{ZnS}_{1}$ & 0.01 & 1 & light sandal \\
\hline $\mathrm{ZnS}_{0.5}$ & 0.005 & 0.5 & light white \\
\hline $\mathrm{ZnS}_{0.1}$ & 0.001 & 0.1 & pure white \\
\hline $\mathrm{ZnS}_{0.05}$ & 0.0005 & 0.05 & light brown \\
\hline
\end{tabular}

solution to milky; then, a white precipitate was formed. The excess water with the dissolved by-product $\mathrm{NaCl}$ $\left(\mathrm{ZnCl}_{2}+\mathrm{Na}_{2} \mathrm{~S} \rightarrow \mathrm{ZnS}+2 \mathrm{NaCl}\right)$ was decanted, and the precipitate was washed in ethanol and then washed four times with deionized water. Since, ethanol can avoid the new formation of $\mathrm{ZnS}$ nanocrystals from undissolved $\mathrm{Na}_{2} \mathrm{~S}$ and $\mathrm{ZnCl}_{2}\left(\mathrm{ZnCl}_{2}\right.$ partially dissolves in ethanol). After washing four times in DI water, the precipitate was again washed in ethanol and the excess ethanol was decanted, and then the precipitate was dried at $60^{\circ} \mathrm{C}$ in air since ethanol evaporates at around $50^{\circ} \mathrm{C}$. After evaporation of the ethanol, a fine powder of $\mathrm{ZnS}$ was obtained and the color of the final powder was seen different for each sample as shown in Table 7.

\section{Effect of trisodium citrate concentration}

The effect of the concentrations of trisodium citrate on $\mathrm{ZnS}$ particle growth was studied by varying trisodium citrate concentration. Here, $\mathrm{ZnCl}_{2}$ and $\mathrm{Na}_{2} \mathrm{~S}$ concentrations were fixed similar to the concentration of the sample $\mathrm{ZnS}_{0.1}$ in the ' $\mathrm{ZnS}$ nanocrystalline powder synthesis by varying sulfur concentration' section based on the results discussed in the 'Results and discussion' section. Stock solutions of $1 \mathrm{M} \mathrm{ZnCl}_{2}$ and $0.1 \mathrm{M} \mathrm{Na}_{2} \mathrm{~S}$ were prepared as in the ' $\mathrm{ZnS}$ nanocrystalline powder synthesis by varying sulfur concentration' section, and then the solutions of trisodium citrate for various concentrations were prepared as shown in Table 8.

Each concentration of trisodium citrate solution was made under magnetic stirring for $10 \mathrm{~min}$ to make it a clear solution, and then each of the trisodium citrate solution was mixed with $10 \mathrm{ml} \mathrm{Na}_{2} \mathrm{~S}$ solution. The stirring

Table 8 Variation of citrate concentration for ZnS nanopowder synthesis

\begin{tabular}{ll}
\hline Samples & Molarity (M) \\
\hline C0 & 0 \\
\hline C1 & 0.5 \\
\hline C2 & 1 \\
\hline C3 & 1.5 \\
\hline C4 & 2 \\
\hline C5 & 3 \\
\hline
\end{tabular}

continued for $1 \mathrm{~h}$ until the solution became light blue, and then the $\mathrm{Na}_{2} \mathrm{~S}$-trisodium citrate solution was added drop by drop using a burette to $10 \mathrm{ml} \mathrm{ZnCl}_{2}$ solution while maintaining the stirring (about $200 \mathrm{rpm}$ ). It was seen that the solution became milky for each drop of $\mathrm{Na}_{2} \mathrm{~S}$ trisodium citrate, and after mixing all the $\mathrm{Na}_{2} \mathrm{~S}$-trisodium citrate solution, a white precipitate was obtained. Then, stirring was stopped to let the white precipitate settle at the bottom of the flask. The excess liquid was decanted, and then the settled white powder was washed in ethanol and then washed four times using DI water as explained in the ' $\mathrm{ZnS}$ nanocrystalline powder synthesis by varying sulfur concentration' section. After washing again with ethanol, the precipitate was taken into a heater which was maintained at about $60^{\circ} \mathrm{C}$ in air, and then finally, a white fine powder was obtained.

\section{Competing interests}

The authors declare that they have no competing interests.

\section{Authors' contributions}

AKT carried out the experiments, examined the results, and drafted the manuscript. AKAU coordinated the project and discussed the results. Both authors read and approved the final manuscript.

\section{Acknowledgements}

The authors thank STIC, Cochin University of Science and Technology, Cochin, Kerala and SAIF, North Eastern Hill University, Shillong, Meghalaya for $X R D$, SEM, FTIR, and TEM

Received: 29 March 2013 Accepted: 4 April 2013

Published: 15 July 2013

\section{References}

1. Suchita, K, Gosavi, SW, Urban, J, Kulkarni, SK: Nanoshell particles: synthesis, properties and applications. Curr. Sci. 91, 8 (2006)

2. Chen, Z-G, Zou, J, Wang, D-W, Yin, L-C, Liu, G, Liu, Q, Sun, C-H, Yao, X, Li, F, Yuan, X-L, Sekiguchi, T, Lu, GQ, Cheng, H-M: Field emission and cathodoluminescence of $\mathrm{ZnS}$ hexagonal pyramids of zinc blende structured single crystals. Adv. Funct. Mater. 19, 484-490 (2009)

3. Sakshi, S, Dhoble, SJ, Singh, P, Ramrakhiani, M: Fabrication of ZnS:Cu/PVA nanocomposite electroluminescence devices for flat panel displays. Adv. Materials Lett. 4(2), 169-173 (2013)

4. Nizamoglu, S, Demir, HV: Excitation resolved color conversion of CdSe/ZnS core/shell quantum dot solids for hybrid white light emitting diodes. J. Appl. Phys. 105, 083112 (2009)

5. Muller, GO, Mach, R, Selle, B, Ohnishi, H: Efficient ZnS-like alkaline earth sulfide electroluminescence. J. Crystal Growth 101, 999-1003 (1990)

6. Wang, X, Xie, Z, Huang, H, Liu, Z, Chen, D, Shen, G: Gas sensors, thermistor and photodetector based on ZnS nanowires. J. Mater. Chem. 22, 6845-6850 (2012). doi:10.1039/C2JM16523F

7. Sorokina, IT, Sorokin, E, Mirov, S, Fedorov, V, Badikov, V, Panyutin, V, Schaffers, Kl: Broadly tunable compact continuous-wave $\mathrm{Cr}^{2+}: \mathrm{ZnS}$ laser. Opt. Lett. 27(12), 1040-1042 (2002)

8. Sumitomo Electric Industries, Ltd: Environmentally-resistant ZnS lens for farinfrared cameras (new products and techniques). Sei Tech. Rev. 71, 113-115 (2010)

9. Onodera, C, Masaaki, Y, Tadayoshi, S, Tsunemasa, T: Threshold current density in ZnS/MgBeZnS quantum well ultraviolet lasers. Optical Rev. 17(3), 159-160 (2010)

10. Gangopadhyay, U, Kyunghea, K, Dhungel, SK, Mangalaraj, D, Park, JH, Yi, J: Application of CBD zinc sulfide (ZnS) film to low cost antireflection coating on large area industrial silicon solar cell. Trans. Electrical and Electronic Materials 5, 1 (2004) 
11. Bredol, M, Matras, K, Szatkowski, A, Sanetra, J, Prodi-Schwa, A: P3HT/ZnS: A new hybrid bulk heterojunction photovoltaic system with very high open circuit voltage. Solar Energy Mater. Solar Cells 93, 662-666 (2009)

12. Hsieh, M-F, Li, JK-J, Lin, JC-A, Huang, S-H, Sperling, RA, Parak, WJ, Chang, WH: Tracking of cellular uptake of hydrophilic CdSe/ZnS quantum dots/ hydroxyapatite composites nanoparticles in MC3T3-E1 osteoblast cells. J. Nanosci. Nanotechnol. 8, 12 (2008)

13. Hussain, S, Won, N, Nam, J, Bang, J, Chung, H, Kim, S: One-pot fabrication of high-quality InP/ZnS (core/shell) quantum dots and their application to cellular imaging. Chem. Phys. Chem. 10, 1466-1470 (2009)

14. Bhadra, R, Singh, VN, Mehta, BR, Datta, P: Studies on some aspects of ZnS nanocrystals for possible applications in electronics. Chalcogenide Lett. 6(5), 189-196 (2009)

15. Lan, C, Gon, J, Jiang, Y, Ding, Q: Fabrication of ZnS/SnO nanowire/ nanosheet hierarchical nanoheterostructure and its photoluminescence properties. Cryst. Eng, Comm (2012). doi:10.1039/C2CE26053K

16. Shaban, SM, Saeed, NM, Raad, MS, Shaban, SM, Saeed, NM, AL-Haddad, RMS: Fabrication and study zinc sulfide schottky barrier detectors. Indian J. Sci. Technol. 4, 4 (2011)

17. Coleman, VA, Jagadish, C: Basic properties and applications of ZnO. In: Jagadish, C, Pearton, S (eds.) Zinc Oxide Bulk, Thin Films and Nanostructures: Processing, Properties, and Applications, pp. 1-20. Elsevier, Oxford (2006)

18. Warada, HC, Ghosh, SC, Hemtanon, B, Thanachayanont, C, Dutt, J: Luminescent nanoparticles of Mn doped ZnS passivated with sodium hexametaphosphate. Sci. Technol. Adv. Mater. 6, 296-301 (2005)

19. Dong, D-Q, Lan, LI, Zhang, X-S, XU, HAN, Hai-Ping, AN: Effect of precursor molar ration of $\mathrm{S}^{2-} / \mathrm{Zn}^{2+}$ on particles size and photoluminescence of $\mathrm{ZnS}$ : $\mathrm{Mn}^{2+}$ nanocrystals. Chin. Phys. Lett. 24(9), 2661 (2007)

20. Yuan-yuan, SHE, Juan, YANG, Ke-qiang, QIU: Synthesis of ZnS nanoparticles by solid-liquid chemical reaction with $\mathrm{ZnO}$ and $\mathrm{Na}_{2} \mathrm{~S}$ under ultrasonic. Trans. Nonferrous Met. Soc. China 20, s211-s215 (2010)

21. Zhao, Z, Geng, F, Cong, H, Bai, J, Cheng, H-M: A simple solution route to controlled synthesis of $\mathrm{ZnS}$ submicrospheres, nanosheets and nanorods. Nanotechnology 17, 4731-4735 (2006). doi:10.1088/0957-4484/17/18/034

22. Williamson, GK, Hall, WH: X-ray line broadening from filed aluminium and wolfram. Acta Metall. 1, 22 (1953). doi:10.1016/0001-6160(53)90006-6

23. Bhattacharjee, B, Ganguli, D, lakoubovskii, K, Stesmans, A, Chaudhuri, S: Synthesis and characterization of sol-gel derived $\mathrm{ZnS}: \mathrm{Mn}^{2+}$ nanocrystallites embedded in a silica matrix. Bull. Mater. Sci. 25(3), 175-180 (2002)

24. Sahu, SN, Nanda, KK: Nanostructure semiconductors:physics and applications. PINSA 67(A, 1), 103-130 (2001)

25. Wang, J, Isshiki, M: Wide-bandgap II-VI semiconductors: growth and properties. In: Kasap, S, Capper, P (eds.) Springer Handbook of Electronic and Photonic Materials, pp. 325-342. Springer, New York (2007)

26. Brus, LE: A simple model for the ionization potential, electron affinity and aqueous redox potentials of small semiconductor crystallites. J. Chem. Phys. 79, 5566-5571 (1983)

27. Üzar, N, Arikan, MÇ: Synthesis and investigation of optical properties of ZnS nanostructures. Bull. Mater. Sci. 34(2), 287-292 (2011)

28. John, R, Sasi Florence, S: Optical, structural and morphological studies of bean-like ZnS nanostructures by aqueous chemical method. Chalcogenide Lett. 7(4), 269-273 (2010)

29. Prabhu, RR, Abdul Khadar, M: Characterization of chemically synthesized CdS nanoparticles. Pramana J. Phys. 65(5), 801-807 (2005)

doi:10.1186/2193-8865-3-56

Cite this article as: Thottoli and Unni: Effect of trisodium citrate

concentration on the particle growth of ZnS nanoparticles. Journal of Nanostructure in Chemistry 2013 3:56.

\section{Submit your manuscript to a SpringerOpen ${ }^{\circ}$ journal and benefit from:}

- Convenient online submission

- Rigorous peer review

- Immediate publication on acceptance

- Open access: articles freely available online

- High visibility within the field

- Retaining the copyright to your article

Submit your next manuscript at $>$ springeropen.com 